Strahlenther Onkol 2014 · 190:26-33 DOI 10.1007/s00066-013-0450-y

Received: 31 July 2013

Accepted: 5 August 2013

Published online: 21 September 2013

(c) The autor(s) 2013. This article is published

with open access at link.springer.com

\author{
M. Guckenberger ${ }^{1} \cdot$ N. Andratschke ${ }^{2} \cdot$ H. Alheit ${ }^{3} \cdot$ R. Holy ${ }^{4}$ C. Moustakis ${ }^{5}$. \\ U. Nestle ${ }^{6} \cdot 0$. Sauer ${ }^{1}$ \\ ${ }^{1}$ Department of Radiation Oncology, University of Würzburg \\ ${ }^{2}$ Department of Radiotherapy and Radiation Oncology, University of Rostock \\ ${ }^{3}$ Distler Radiation Oncology, Bautzen/Pirna \\ ${ }^{4}$ Department of Radiation Oncology, RWTH Aachen University, Aachen \\ ${ }^{5}$ Department of Radiation Oncology, University of Münster \\ ${ }^{6}$ Department of Radiation Oncology, University of Freiburg
}

\title{
Definition of stereotactic body radiotherapy
}

\section{Principles and practice for the treatment of stage I non-small cell lung cancer}

\section{Definition of SBRT}

tic body radiotherapy (SBRT) were transferred from cranial stereotactic radiotherapy/radiosurgery in the mid-1990s by pioneering work at the Karolinska Hospital in Sweden [1]. This concept was quickly adopted and further developed in Japan [2] and Germany [3, 4]. At the beginning, SBRT was predominantly defined by frame-based stereotactic patient setup for accurate delivery of conformal dose distributions to extracranial targets in hypofractionated irradiation schemes. Nowadays however, a commonly accepted definition of SBRT does not exist. This is because frame-based stereotactic patient setup has been replaced by image guidance, which renders the term stereotactic misleading.

The Stereotactic Radiotherapy Working Group was asked by the German Society of Radiation Oncology (Deutschen Gesellschaft für Radioonkologie, DEGRO) to provide a definition of SBRT and to give an evidence-based review of current SBRT practice. This article will focus on the definition of SBRT, as well as the indications for and practice and outcome of SBRT for early stage non-small cell lung cancer (NSCLC).
National working groups in several different countries have reported their definitions of SBRT. The definitions of SBRT provided by the American Association of Physics in Medicine (AAPM) Task Group 101; the American Society for Therapeutic Radiology and Oncology and the American College of Radiology (ASTRO and ACR); the Canadian Association of Radiation Oncology-Stereotactic Body Radiotherapy (CARO-SBRT) and the National Radiotherapy Implementation Group of the UK $[5,6,7,8]$ all agree on the following items: SBRT is (1) a method of external beam radiotherapy (EBRT) that (2) accurately delivers a (3) high dose of irradiation in (4) one or few treatment fractions to an (5) extracranial target.

These essential components of the SBRT definition are specified in more detail below:

1. SBRT can be adequately performed with either traditional linear accelerators equipped with suitable image-guidance technology, accelerators specifically adapted for SBRT or dedicated delivery systems. Additionally, the principles of SBRT apply for both photon and particle therapy.
2. It is of fundamental importance that the entire SBRT workflow be systematically optimized and that appropriate quality assurance (QA) measures are implemented. From a clinical perspective, the term "accurate" covers disease staging; multidisciplinary discussion of the indications for SBRT; tumor site adjusted imaging with appropriate spatial and temporal resolution for target and organ at risk (OAR) definition; highly conformal treatment; image-guided patient setup; active or passive intrafraction motion management and follow-up (preferably at the treating institution). From a physics perspective, SBRT requires additional and more sophisticated QA procedures compared to conventional radiotherapy. These include system-specific end-to-end tests for both static and moving targets, as well as verification of the alignment of imaging and treatment isocenters prior to SBRT on a daily basis.

3. Radiation doses are at least equivalent to radical doses in conventional fractionation.

4. Radiation doses are delivered in few fractions (usually but not necessarily in a maximum of 10 fractions). Adjustment of single-fraction dose and 
total dose to volume and location of the target is essential.

5. The target is accurately localized using tumor site specific imaging modalities. Simultaneously, the target needs to be spatially separated from critical OARs, without diffuse infiltration into these. Only the macroscopic target and small, immediately adjacent volumes of potential microscopic spread are treated in SBRT.

The term "stereotactic" is still considered appropriate for SBRT, even if no framebased patient setup using external stereotactic coordinates is performed; the external coordinates are replaced by the internal coordinates of the image guidance procedure. These images must either visualize and locate the target itself or surrogate anatomical structures/fiducial markers that are closely correlated to the target.

Stereotactic ablative radiotherapy (SABR) has been proposed by an international group of authors as an alternative to SBRT [9]. However, our opinion on the appropriateness of "ablative" differs because it does not accurately describe the radiobiology and clinical outcome of SBRT in all its variations. Techniques like radiofrequency ablation (RFA) are ablative irrespective of the normal or neoplastic nature of the tissue in the treated volume, which makes treatment of tumors abutting critical serial OARs impossible. In contrast, SBRT allows tumoricidal treatment of such targets while sparing the OARs through the differences in radiosensitivity of normal and cancerous tissue, as well as through fractionation effects.

\section{SBRT for early stage NSCLC}

\section{Rationale for SBRT}

After detection of NSCLC at an early stage (as is the case in $20-30 \%$ of all patients), the best overall survival (OS) with cure rate in the majority of the patients is achieved by surgical lobectomy and systematic mediastinal lymph node dissection. However, surgical resection is not possible in a substantial proportion of patients-about $20 \%$ of all patients with stage I NSCLC [10]-because of comor- bidities or insufficient pulmonary function resulting from tobacco abuse and consequent chronic obstructive pulmonary disease (COPD). This fraction of inoperable patients is expected to further increase due to aging western populations: only $40 \%$ of patients aged 75 years or older are treated surgically for stage I NSCLC in the Netherlands [11]. If no treatment is offered to these patients, cancer leads to death within few years despite its early stage [10].

In cases of contraindication for radical lobectomy, the standard treatment options are best supportive care (BSC), conventionally fractionated radiotherapy and sublobar resection. The therapy of choice depends on the patient's performance status, age and comorbidities.

Based on the California Cancer Center registry, $7 \%$ of all patients with stage I NSCLC are treated with BSC alone because their life expectancy is considered too short for curative treatment [10]. Among the elderly population, this proportion of untreated patients increases to $30 \%[11,12]$. However, 5-year lung cancer specific survival rates are less than $20 \%$ in untreated patients, indicating the need for a curative treatment option that is effective and simultaneously safe for this patient population.

Conventionally fractionated radiotherapy is an established curative treatment option for stage I NSCLC, with 3-year OS rates of about $30 \%$ [13]. However, local tumor relapse is the most frequent cause of treatment failure after irradiation with conventionally fractionated doses of 6066 Gy $[13,14]$. Retrospective studies have demonstrated a dose-response relationship for local tumor control and disease specific survival in NSCLC $[15,16,17]$, which clearly indicates the need for a radiotherapy methodology that enables a safe intensification of treatment.

Sublobar resection is practiced in borderline operable patients as an alternative to lobectomy. This technique spares lung tissue and preserves pulmonary function compared to lobectomy. However, the results of a randomized controlled trial [18] indicate that this is associated with inferior oncological outcome.
Clinical outcome after SBRT

for early stage NSCLC and

implications for patient selection

\section{SBRT vs. BSC in the elderly population and patients with severe pulmonary comorbidities}

Two recent population-based analyses from the Netherlands [11, 12] and one from the US [19] demonstrated an improvement in OS for stage I NSCLC by the introduction of SBRT into the elderly patient population. OS was improved by shifting patients from BSC or conventionally fractionated radiotherapy to SBRT, treatment options which are both inferior to SBRT. Further studies showed that SBRT is safely practiced in patients with severe pulmonary comorbidities and very poor pretreatment pulmonary function and toxicity was not increased in these high-risk patient populations [20, 21]. Consequently, SBRT should be offered to all patients-irrespective of advanced age or pre-existing pulmonary comorbidities-unless their survival expectancy is very short. The SBRT characteristics of a noninvasive treatment delivered in a few fractions on an outpatient basis are expected to enhance acceptability in these patient cohorts.

\section{SBRT vs. conventionally fractionated radiotherapy in medically inoperable patients}

Several prospective phase II trials of SBRT in medically inoperable stage I NSCLC patients have reported local tumor control rates of $84-98 \%[22,23,24,25,26,27]$, demonstrating consistent results despite differences in SBRT methodology. This improved local tumor control compared to conventional radiotherapy [13] transfers into improved OS, as demonstrated in meta- [28] and population-based analyses [19]: 3 -year OS is approximately $50 \%$ after SBRT, with pretreatment comorbidities being a strong predictor for OS [29]. Based on these findings and the 1.2013 version of the National Comprehensive Cancer Network (NCCN) Guidelines for NSCLC [30], SBRT is today considered superior to conventionally fractionated radiotherapy and is the standard of care for medically inoperable patients. 


\section{SBRT vs. RFA}

RFA has been introduced as a minimally invasive treatment option for stage I NSCLC. No study has performed a direct comparison between SBRT and RFA, but a recent literature review reported improved local tumor control, cancer specific survival and OS after SBRT compared to RFA [31]. Additionally, toxicity and 30day mortality [32] were lower after SBRT, resulting in the conclusion that SBRT should be proposed as the initial nonsurgical treatment in high-risk patients.

\section{SBRT vs. sublobar resection in high surgical risk patients}

There are few studies directly comparing SBRT and sublobar resection for early stage NSCLC. Grills et al. [33] performed a single-institution comparison between SBRT and wedge resection. These authors reported improved local tumor control after SBRT, while no differences in regional control and cancer specific survival were observed. The previously cited US population-based analysis showed identical OS and cancer specific survival rates for SBRT and sublobar resection [19]: 30day mortality rates were 0 and $1.2 \%$ after SBRT and sublobar resection, respectively. Consequently, current data support both SBRT and sublobar resection as viable treatment alternatives for high surgical risk patients. The results of a currently recruiting American College of Surgeons Oncology Group randomized trial comparing SBRT and sublobar resection (ACOSOG-Z4099) are awaited.

\section{SBRT vs. lobectomy for medically operable patients refusing surgical resection}

The criteria for being fit enough to undergo lobectomy are described in national and international guidelines. Lobectomy is considered to be the treatment of choice for stage I NSCLC if these criteria are met. Few studies have reported outcome after SBRT where surgical resection was refused by the patients. Two Japanese and Dutch studies described excellent OS rates of $70 \%$ after 5 years [34] and $85 \%$ at 3 years [35], respectively. Two recent matched-pair analyses reported equivalent OS [36] and equivalent disease-free survival rates [37] after SBRT and lobecto-

Strahlenther Onkol 2014 · 190:26-33 DOI 10.1007/s00066-013-0450-y

(c) The autor(s) 2013. This article is published with open access at link.springer.com

\section{Guckenberger · N. Andratschke $\cdot$ H. Alheit $\cdot$ R. Holy $\cdot$ C. Moustakis $\cdot$ U. Nestle $\cdot$ O. Sauer Definition of stereotactic body radiotherapy. Principles and practice for the treatment of stage I non-small cell lung cancer}

\section{Abstract}

This report from the Stereotactic Radiotherapy Working Group of the German Society of Radiation Oncology (Deutschen Gesellschaft für Radioonkologie, DEGRO) provides a definition of stereotactic body radiotherapy (SBRT) that agrees with that of other international societies. SBRT is defined as a method of external beam radiotherapy (EBRT) that accurately delivers a high irradiation dose to an extracranial target in one or few treatment fractions. Detailed recommendations concerning the principles and practice of SBRT for early stage non-small cell lung cancer (NSCLC) are given. These cover the en- tire treatment process; from patient selection, staging, treatment planning and delivery to follow-up. SBRT was identified as the method of choice when compared to best supportive care (BSC), conventionally fractionated radiotherapy and radiofrequency ablation. Based on current evidence, SBRT appears to be on a par with sublobar resection and is an effective treatment option in operable patients who refuse lobectomy.

Keywords

Organs at risk - Survival · Toxicity - Patient positioning · Quality assurance

\section{Definition der stereotaktischen Strahlentherapie. Behandlung des nichtkleinzelligen Bronchialkarzinoms (NSCLC) Grad I}

\section{Zusammenfassung}

Die Arbeitsgruppe „Stereotaktische Radiotherapie" der Deutschen Gesellschaft für Radioonkologie (DEGRO) erarbeitete eine Definition der Körperstereotaxie (SBRT), die sich an vorhandene internationale Definitionen anlehnt: Die SBRT ist eine Form der perkutanen Strahlentherapie, die mit hoher Präzision eine hohe Bestrahlungsdosis in einer oder wenigen Bestrahlungsfraktionen in einem extrakraniellen Zielvolumen appliziert. Zur Praxis der SBRT beim nichtkleinzelligen Bronchialkarzinom (NSCLC) im frühen Stadium werden detaillierte Empfehlungen gegeben, die den gesamten Ablauf der Behandlung von der Indikationsstellung, Staging, Be- handlungsplanung und Applikation sowie Nachsorge umfassen. Die Körperstereotaxie wurde als Methode der Wahl im Vergleich zu Best Supportive Care, zur konventionell fraktionierten Strahlentherapie sowie zur Radiofrequenzablation identifiziert. Die Ergebnisse nach SBRT und sublobärer Resektion erscheinen auf aktueller Datenbasis ebenbürtig. Die SBRT ist die Methode der Wahl, wenn Patienten einen operativen Eingriff in Form der Lappenresektion ablehnen.

\section{Schlüsselwörter}

Risikoorgane - Überleben · Toxizität .

Patientenpositionierung · Qualitätssicherung my. Consequently, SBRT is a viable treatment option in the situation of surgical treatment being refused by the patient.

\section{Recommendations for clinical practice of SBRT in early stage NSCLC}

\section{Clinical evaluation}

Careful assessment of performance status is important to enable a sensible therapy concept. Perioperative morbidity is associated with older age ( $>70$ years) and the presence of comorbidities [38, 39]. Therefore, pulmonary function tests, as well as cardiac and performance status assessment are recommended before estimat- ing the operative risk. As a corollary of this, the indication for SBRT should be discussed in an interdisciplinary tumor board.

\section{Histopathological confirmation of disease}

Histopathological confirmation of disease is recommended. Transbronchial biopsy or transthoracic needle aspiration are primary methods. Nevertheless, demonstration of malignancy is sometimes impossible or associated with an unacceptably high risk because of the medical and/or pulmonary comorbidities of the patient. In this case, radiological criteria of malignancy should be consulted. 
Swensen et al. [40] described a prediction model to estimate the probability of malignancy in solitary pulmonary nodules (SPN) based on clinical and radiographic characteristics. This model was validated by Herder et al. [41]. Inclusion of fluorodeoxyglucose positron-emission tomography (FDG-PET) imaging might further improve the accuracy of the prediction model $[42,43]$. If malignancy is highly likely based on the described criteria, immediate SBRT without histopathological confirmation is justified [44], as is also standard practice in thoracic surgery [45]. Repeated imaging to evaluate the growth pattern is an option in patients with a borderline risk of malignancy, but this might put the patient at risk of disease progression in the time interval [46].

\section{Staging of disease}

In accordance with other groups [47], the DEGRO working group recommends the following staging procedures prior to SBRT: a CT scan of the chest including the upper abdomen using intravenous contrast is mandatory. A whole body FDGPET/CT scan should be performed in all cases. The added value of FDG-PET lies in the higher diagnostic accuracy for the detection of nodal metastases (negative predictive value: $90 \%$ ) [48, 49]; furthermore, distant metastases and clinically relevant second malignancies can be excluded. The PET/CT scan should not be older than 6 weeks. In case of pathological FDG uptake in mediastinal lymph nodes, further histopathological evaluation, e.g. by endoscopic ultrasound (EUS)- or endobronchial ultrasound (EBUS)-guided biopsy is mandatory. If the situation is still unclear, a mediastinoscopy may be necessary.

After exclusion of nodal metastases, SBRT is recommended for early stage NSCLC with a maximum tumor diameter $\leq 5 \mathrm{~cm}$. Only limited data are available about the safety and efficacy of SBRT for lesions larger than $5 \mathrm{~cm}$, where the risk of toxicity and occult systemic disease might be increased.

\section{Imaging for target volume definition}

Obviously, all images must be acquired in the treatment position. The planning CT scan should include the entire lung volume. Acquiring CT scans with a slice thickness of $2-3 \mathrm{~mm}$ is recommended. Use of intravenous contrast for CT scanning improves delineation of centrally located primary tumors. However, the use of synchronous intravenous contrast with four-dimensional CT (4D-CT) scans of the thorax is not established.

Due to the risk of artifacts and systematic errors introduced by the nonrepresentative nature of the captured breathing position, the use of a 4D-CT (also known as respiration-correlated CT) scan is strongly recommended for treatment planning and also allows for the evaluation of motion management strategies.

\section{Target volume concept and motion management strategy}

A gross tumor volume (GTV) should be defined based on CT findings in lung and soft tissue windows including all small spiculae. Most centers do not use clinical target volume (CTV) margins to account for microscopic tumor extensions. However, practices pertaining to CTV definition are inconsistent. Caution is therefore advised when applying this concept to SBRT target volume definition, as the applied safety margins may unnecessarily increase target volumes.

Integration of breathing-induced target motion into the target volume concept is a prerequisite for ensuring proper tumor targeting in individual patients. Clinical implementation depends on the respective motion management strategy, which in turn is required for SBRT.

Several different approaches can be applied and have already been implemented into routine practice: continuous irradiation during free breathing using (a) the internal target volume concept (ITV; most commonly practiced), (b) the mean target position concept [50] or (c) realtime tumor tracking. Irradiation in specific breathing phases is performed using (a) gated beam delivery, (b) voluntary breath holding or (c) breath holding using the Active Breathing Coordinator (Elekra, Stockholm, Sweden). Multiple planning studies reported reduced safety margins by the use of individually tailored patient motion compensation strategies compared to population-based margins.
Although patient-specific motion management is strongly recommended, it is important to note that no prospective trials have used advanced motion management strategies. Furthermore, no benefit of advanced motion management strategies like gating or tracking has been found for motion amplitudes $<10-15 \mathrm{~mm}$ $[50,51]$.

\section{Dose, fractionation and prescription}

Wherever possible, dose prescription and reporting should comply with the International Commission on Radiation Units (ICRU) Report 83. ICRU recommends prescribing to the median (D50), or alternatively, to the mean $\left(D_{\text {mean }}\right)$ dose. Based on experiences with cranial stereotactic radiotherapy, SBRT is practiced using inhomogeneous dose distributions within the planning target volume (PTV); maximum PTV doses range between 105 and $150 \%$ of the prescribed PTV-encompassing dose. Effective doses to the GTV further vary according to the applied GTVto-PTV safety margins and the size of the macroscopic tumor. We therefore recommend reporting minimum (D95 or D98) and maximum (D05 or D02) PTV doses-where DX is the minimum dose received by $\mathrm{X} \%$ of the volume-in addition to the doses delivered to the GTV. Ideally, mean dose and the standard deviation of the mean dose should be reported as well as the afore mentioned dose levels. A sensible conformity index (CI) is the one proposed by Paddick [52]. If possible, this CI should be reported.

Normal tissue risk-adapted fractionation is highly recommended, with 1-10 delivered fractions depending on the size and central/peripheral location of the target [53].

Several groups independently demonstrated a clear dose-response relationship for local tumor control $[54,55,56,57]$ : a minimum biologically effective dose (BED; $\alpha / \beta$ ratio: $10 \mathrm{~Gy}$ ) of $>100$ Gy to the PTV) achieved local tumor control rates $>90 \%$. It could be demonstrated that this dose-dependent increase in local control translated into improved OS $[54,58]$. A recent meta-analysis reported the best OS rates for medium to high SBRT doses of 83.2-146 Gy BED; OS was worse af- 
Tab. 1 Normal tissue constraints according to published major clinical studies. Radiation Therapy Oncology Group (RTOG) protocols can be found on the RTOG website at http://www.rtog.org/ClinicalTrials/ProtocolTable.aspx

\begin{tabular}{|c|c|c|c|c|c|}
\hline Organ at risk & $\begin{array}{l}\text { Single fraction } \\
\text { (RTOG 0915) }\end{array}$ & $\begin{array}{l}\text { Three fractions } \\
\text { (RTOG 0618/1021) }\end{array}$ & $\begin{array}{l}\text { Four fractions } \\
\text { (RTOG 0915) }\end{array}$ & $\begin{array}{l}\text { Five fractions } \\
\text { (RTOG 0813) }\end{array}$ & $\begin{array}{l}\text { Eight fractions } \\
\text { (Haasbeck et al. } 2011 \text { [76]) }\end{array}$ \\
\hline Trachea and large bronchus & $D_{\max } 20.2 \mathrm{~Gy}$ & $D_{\max } 30 \mathrm{~Gy}$ & $\begin{array}{l}D_{\max } 34.8 \mathrm{~Gy} \\
15.6 \mathrm{~Gy}<4 \mathrm{cc}\end{array}$ & $\begin{array}{l}D_{\max } 105 \%{ }^{a} \\
18 G y<5 c c^{b}\end{array}$ & $D_{\max } 44 \mathrm{~Gy}$ \\
\hline Heart & $\begin{array}{l}D_{\max } 22 \mathrm{~Gy} \\
16 \mathrm{~Gy}<15 \mathrm{cc}\end{array}$ & $D_{\max } 30 \mathrm{~Gy}$ & $\begin{array}{l}D_{\max } 34 \mathrm{~Gy} \\
28 \mathrm{~Gy}<15 \mathrm{cc}\end{array}$ & $\begin{array}{l}D_{\max } 105 \%{ }^{a} \\
32 \mathrm{~Gy}<15 \mathrm{cc}\end{array}$ & - \\
\hline Esophagus & $\begin{array}{l}D_{\max } 15.4 \mathrm{~Gy} \\
11.9 \mathrm{~Gy}<5 \mathrm{cc}\end{array}$ & $\begin{array}{l}D_{\max } 25.2 \mathrm{~Gy} \\
17.7 \mathrm{G}<5 \mathrm{cc}\end{array}$ & $\begin{array}{l}D_{\max } 30 \mathrm{~Gy} \\
18.8 \mathrm{~Gy}<5 \mathrm{cc}\end{array}$ & $\begin{array}{l}D_{\max } 105 \% \%^{a} \\
27.5 \mathrm{~Gy}<5 \mathrm{cc}^{\mathrm{b}}\end{array}$ & $D_{\max } 40$ Gy \\
\hline Brachial plexus & $\begin{array}{l}D_{\max } 17.5 \mathrm{~Gy} \\
14 \mathrm{~Gy}<3 \mathrm{cc}\end{array}$ & $\begin{array}{l}D_{\max } 24 \mathrm{~Gy} \\
20.4 \mathrm{~Gy}<3 \mathrm{cc}\end{array}$ & $\begin{array}{l}D_{\max } 27,2 \mathrm{~Gy} \\
23.6 \mathrm{~Gy}<3 \mathrm{cc}\end{array}$ & $\begin{array}{l}D_{\max } 32 G y \\
30 G y<3 c c\end{array}$ & $D_{\max } 36 G y$ \\
\hline Chest wall & $\begin{array}{l}D_{\max } 30 \mathrm{~Gy} \\
22 \mathrm{~Gy}<1 \mathrm{cc}\end{array}$ & $\begin{array}{l}30 \mathrm{~Gy}<30 \mathrm{cc} \\
60 \mathrm{~Gy}<3 \mathrm{cc}[77,78]\end{array}$ & $\begin{array}{l}D_{\max } 27,2 \mathrm{~Gy} \\
32 \mathrm{~Gy}<1 \mathrm{cc}\end{array}$ & $\begin{array}{l}30 \mathrm{~Gy}<30 \mathrm{cc} \\
60 \mathrm{~Gy}<3 \mathrm{cc}[77,78]\end{array}$ & - \\
\hline Spinal cord & $\begin{array}{l}D_{\max } 14 \mathrm{~Gy} \\
10 \mathrm{~Gy}<0.35 c c\end{array}$ & $\begin{array}{l}D_{\max } 18 \mathrm{~Gy} \\
\text { (RTOG 0236) }\end{array}$ & $\begin{array}{l}\mathrm{D}_{\max } 26 \mathrm{~Gy} \\
28.8 \mathrm{~Gy}<0.35 \mathrm{cc}\end{array}$ & $\begin{array}{l}D_{\max } 30 \mathrm{~Gy} \\
22.5 \mathrm{~Gy}<0.25 \mathrm{cc}\end{array}$ & $\mathrm{D}_{\max } 28 \mathrm{~Gy}$ \\
\hline
\end{tabular}

ter SBRT with >146 Gy BED, indicating a detrimental effect of excessively high doses [59].

Three fractions of $15 \mathrm{~Gy}$ with a dose maximum of $150 \%$ was the preferred fractionation scheme in the German and Austrian patterns of care analysis and resulted in local tumor control rates of $>90 \%$ [60]. This fractionation scheme of $3 \times 15$ Gy as D95 or D98 to the PTV with a D05 or D02 PTV dose of $150 \%$ is therefore recommended for peripherally located NSCLC $\leq 5 \mathrm{~cm}$ in diameter. However, it has to be mentioned that this regimen was planned using type A (pencil beam) dose calculation algorithms in $80 \%$ of cases, which might have overestimated the true dose by about $10 \%$ [61]. Additionally, this recommendation is lower than the $3 \times 18 \mathrm{~Gy}$ fractionation scheme that is used most frequently internationally.

Limited data are available concerning the safety and efficacy of SBRT for centrally located lesions [62]. Particularly where very high single fraction doses were applied, lethal outcomes have been observed [63]. Therefore, treatment of central lesions should preferably be performed within prospective trials such as the European Organisation for Research and Treatment of Cancer (EORTC) LungTECH trial. Until then, a recommended fractionation scheme for experienced centers is $8 \times 7.5$ Gy as D95 or D98 to the PTV; dose inhomogeneity within the PTV should be limited to $125 \%$ [62].

\section{OAR tolerance doses}

It is of utmost importance to note that none of the published tolerance doses for SBRT have been formally validated. Nevertheless, as the toxicity after SBRT for peripheral lesions with the published OAR tolerance doses seems to be acceptable (grade $\geq$ II less than 10\%), adherence to such published protocols is strongly recommended (• Tab. 1).

Patients need to be informed about the following SBRT-specific toxicities: (1) Toxicities in up to $10 \%$ of cases depending on tumor size and location: radiation-induced pneumonitis, rib fractures, chest wall pain. (2) Rarely observed toxicities: pleural and pericardial effusion, stricture of central airway structures, dyspnea, bleeding. (3) For more central locations, the low risk of life-threatening necrosis/fistula of neighboring organs such as esophagus, bronchi and large vessels, as well that of cardiac arrhythmias should be mentioned (depending on the exact tumor location).

\section{Treatment planning}

Photon energy should be below $10 \mathrm{MeV}$ in order to avoid excess penumbra blurring. A leaf width of $5 \mathrm{~mm}$ at the isocenter is considered sufficiently small. The voxel size of the calculation grid should be $2 \mathrm{~mm}$ or less.

For dose calculation, heterogeneity correction and use of a type B dose calculation algorithm [64] is mandatory to achieve an accuracy of dose calculation exceeding $2 \%$.

All prospective trials used three-dimensional conformal radiotherapy (3DCRT) for treatment planning. Intensitymodulated radiotherapy (IMRT) and advanced rotational techniques like volumetric-modulated arc therapy (VMAT) or RapidArc (Varian Medical Systems, Palo Alto, CA, USA) have the potential to increase conformity and homogeneity. The biological effect of these differences and the potential interplay of multileaf collimator (MLC) and tumor motion need to be considered. Flattening filter free irradiation will further reduce treatment delivery times.

\section{Patient immobilization and setup}

Customized patient immobilization was used in the majority of trials and is highly recommended to minimize intrafractional patient motion.

Internal shifts of the pulmonary target relative to the bony structures are the major source of positioning uncertainties [65, 66]. These effects cannot be countered by stereotactic setup or bone imaging. Therefore, daily pretreatment imaging is required for online correction of setup errors and base-line shifts. Imaging needs to visualize either the lung tumor directly or implanted markers that act as a surrogate for tumor position. Breathing-induced target motion must be fully integrated into the image-guided radiotherapy (IGRT) process. Post- and/or mid-SBRT imaging 
is recommended for QA, particularly in single fraction SBRT. Several methodologies for image guidance are commercially available (cone beam CT, in-room CT and orthogonal x-rays for fiducial control) and superiority of one method over the other has not been demonstrated.

Interfractional tumor shifts might occur towards critical OARs and their correction by IGRT isocenter adjustment might result in increased OAR doses. Volumetric IGRT is required to visualize and quantify such effects. Methods for avoiding OAR overdosage are incorporation of safety margins for critical OARs (planning organ at risk volume, PRV, concept), repositioning or even replanning if critical thresholds are exceeded.

\section{Follow-up}

Clinical and radiological follow-up should be performed at the treating institution. CT imaging should be performed every 3 months for 2 years and every 6 months thereafter for another 3 years. This examination frequency has not been validated and should be adjusted to the patient's performance status and suitability for salvage treatment.

Mass-like fibrosis within the highdose region is observed after the majority of SBRT treatments $[67,68,69,70]$ and its differentiation from local failure is difficult. FDG-PET is recommended in cases where CT-based morphological differentiation of fibrosis and recurrence is not possible. However, FDG-PET results should be interpreted with caution within 6-9 months after SBRT due to the possibility of false-positive findings arising from inflammation processes [71]. Due to the risk of bleeding, bronchoscopic and/ or transthoracic biopsies are only recommended if local recurrence is suspected and clinically relevant salvage treatment options are available.

\section{Physical and QA requirements for safe SBRT practice}

It is recommended that SBRT be performed by a team consisting of a radiation oncologist, a medical physicist and technicians (radiographers, therapists). All members of the team should have attended dedicated SBRT teaching activities or- ganized within the institution, by national or international societies or in an industrial setting.

Treatment should follow written standard operating procedures (SOPs), which are adjusted according to national regulations, the institution-specific equipment and training and education of the individual radiotherapy team members.

Comprehensive practical guidelines for SBRT are given in several international reports $[5,6,7,8,47]$. For Germany it is recommended to apply the appropriate norms defined by the Deutsche Institut für Normung (DIN). In this context the following reports are particularly relevant: DIN 6847-5, DIN 6858-1, DIN 6870-1, DIN 6873-5, DIN 6875-1 and DIN 6875-2.

Verification of the accuracy of the entire SBRT treatment chain is mandatory. This includes all imaging processes, the dose calculation engine, the MLC sequencing, the monitor unit calculation, the monitor calibration, patient positioning, the tracking or gating devices and so forth. Most steps are part of the regular commissioning and QA procedures.

It is paramount to verify that the radiation isocenter coincides with the mechanical isocenter-including couch rotation-and that the lasers are aligned to the radiation isocenter. The same is true for the imaging isocenter. End-to-end tests are recommended for overall uncertainty estimates. If a sufficiently precise independent and redundant localization is not used for every application, the alignment of the IGRT and the treatment isocenter should be tested daily.

\section{Radiobiological considerations of SBRT}

Detailed understanding of the radiobiology of SBRT is still lacking. In contrast to conventional fractionated radiotherapy, there is no repopulation, reoxygenation or redistribution of tumor cells in single fraction SBRT. Even hypofractionated schedules still provide short overall treatment times and therefore at least accelerated repopulation has not to be considered. Additional effects of high fraction doses in SBRT may be vascular and [72] immune effects [73].
Although the linear quadratic (LQ) model is widely used in the community and has proven feasible for the description of SBRT outcome in several clinical reports, the applicability of this modality has been questioned because it has not been validated for very high single doses [74]. Most likely it is accurate up to single fraction doses of 15 Gy [75]. For higher fraction doses the model might overestimate the biological effectiveness, particularly for low $\alpha / \beta$ values. This may lead to underdosage of tumors with lower $\alpha / \beta$ values, such as prostate cancer, whereas it may be less critical for tumors with higher $\alpha / \beta$ values, such lung cancer. However, for normal tissues it should provide a more conservative approach. Alternative models have been proposed but are more complicated to use and have not been better validated using clinical data. In conclusion, the LQ model should be used, with caution, until more accurate models have been validated.

\section{Conclusion}

This report provides a definition of SBRT that is agreement with that of other international societies. Detailed recommendations for principles and practice of SBRT for early stage NSCLC are given. These cover the entire treatment process; from patient selection, disease staging, treatment planning and delivery to follow-up.

\section{Corresponding address}

Prof. Dr. M. Guckenberger

Department of Radiation Oncology, University of Würzburg

Josef-Schneider-Str. 11, 97080 Würzburg

Germany

guckenberger_m@klinik.uni-wuerzburg.de

\section{Compliance with ethical guidelines}

Conflict of interest. M. Guckenberger, N. Andratschke, H. Alheit, R. Holy, C. Moustakis, U. Nestle and $O$. Sauer state that there are no conflicts of interest.

The accompanying manuscript does not include studies on humans or animals. 


\section{Open access}

This article is distributed under the terms of the Creative Commons Attribution License which permits any use, distribution and reproduction in any medium, provided the original author(s) and the source are credited.

\section{References}

1. Lax I, Blomgren H, Naslund I, Svanstrom R (1994) Stereotactic radiotherapy of malignancies in the abdomen. Methodological aspects. Acta Oncol 33:677-683

2. Uematsu M, Shioda A, Tahara K et al (1998) Focal, high dose, and fractionated modified stereotactic radiation therapy for lung carcinoma patients: a preliminary experience. Cancer 82:1062-1070

3. Wulf J, Hadinger U, Oppitz U et al (2000) Stereotactic radiotherapy of extracranial targets: CT-simulation and accuracy of treatment in the stereotactic body frame. Radiother Oncol 57:225-236

4. Herfarth KK, Debus J, Lohr F et al (2000) Extracranial stereotactic radiation therapy: set-up accuracy of patients treated for liver metastases. Int J Radiat Oncol Biol Phys 46:329-335

5. Benedict SH, Yenice KM, Followill D et al (2010) Stereotactic body radiation therapy: the report of AAPM Task Group 101. Med Phys 37:4078-4101

6. Potters L, Kavanagh B, Galvin JM et al (2010) American Society for Therapeutic Radiology and Oncology (ASTRO) and American College of Radiology (ACR) practice guideline for the performance of stereotactic body radiation therapy. Int J Radiat Oncol Biol Phys 76:326-332

7. Kirkbride P, Cooper T (2011) Stereotactic body radiotherapy. Guidelines for commissioners, providers and clinicians: a national report. Clin Oncol 23:163-164

8. Sahgal A, Roberge D, Schellenberg D et al (2012) The Canadian Association of Radiation Oncology scope of practice guidelines for lung, liver and spine stereotactic body radiotherapy. Clin Oncol 24(9):629-639

9. Loo BW, Chang JY, Dawson LA et al (2011) Stereotactic ablative radiotherapy: what's in a name? Pract Radiat Oncol 1:38-39

10. Raz DJ, Zell JA, Ou SH et al (2007) Natural history of stage I non-small cell lung cancer: implications for early detection. Chest 132:193-199

11. Haasbeek CJ, Palma D, Visser O et al (2012) Earlystage lung cancer in elderly patients: a populationbased study of changes in treatment patterns and survival in the Netherlands. Ann Oncol 23:27432747

12. Palma D, Visser $O$, Lagerwaard FJ et al (2010) Impact of introducing stereotactic lung radiotherapy for elderly patients with stage I non-small-cell lung cancer: a population-based time-trend analysis. $J$ Clin Oncol 28:5153-5159

13. Rowell NP, Williams CJ (2001) Radical radiotherapy for stage $1 /$ II non-small cell lung cancer in patients not sufficiently fit for or declining surgery (medically inoperable). Cochrane Database Syst Rev 2:CD002935

14. Sibley GS, Jamieson TA, Marks LB et al (1998) Radiotherapy alone for medically inoperable stage I non-small-cell lung cancer: the Duke experience. Int J Radiat Oncol Biol Phys 40:149-154

15. Martel MK, Ten Haken RK, Hazuka MB et al (1999) Estimation of tumor control probability model parameters from 3-D dose distributions of non-small cell lung cancer patients. Lung Cancer 24:31-37
16. Willner J, Baier K, Caragiani E et al (2002) Dose, volume, and tumor control prediction in primary radiotherapy of non-small-cell lung cancer. Int J Radiat Oncol Biol Phys 52:382-389

17. Partridge M, Ramos M, Sardaro A, Brada M (2011) Dose escalation for non-small cell lung cancer: analysis and modelling of published literature. Radiother Oncol 99:6-11

18. Ginsberg RJ, Rubinstein LV (1995) Randomized trial of lobectomy versus limited resection for T1 NO non-small cell lung cancer. Lung Cancer Study Group. Ann Thorac Surg 60:615-622 (discussion 622-613)

19. Shirvani SM, Jiang J, Chang JY et al (2012) Comparative effectiveness of 5 treatment strategies for early-stage non-small cell lung cancer in the elderly. Int J Radiat Oncol Biol Phys 84:1060-1070

20. Palma D, Lagerwaard F, Rodrigues $\mathrm{G}$ et al (2011) Curative treatment of stage I non-small-cell lung cancer in patients with severe COPD: stereotactic radiotherapy outcomes and systematic review. Int $J$ Radiat Oncol Biol Phys (Epub)

21. Guckenberger M, Kestin LL, Hope AJ et al (2012) Is there a lower limit of pretreatment pulmonary function for safe and effective stereotactic body radiotherapy for early-stage non-small cell lung cancer? JThorac Oncol 7:542-551

22. Nagata Y, Takayama K, Matsuo Y et al (2005) Clinical outcomes of a phase I/II study of $48 \mathrm{~Gy}$ of stereotactic body radiotherapy in 4 fractions for primary lung cancer using a stereotactic body frame. Int J Radiat Oncol Biol Phys 63:1427-1431

23. Baumann P, Nyman J, Hoyer M et al (2009) Outcome in a prospective phase II trial of medically inoperable stage I non-small-cell lung cancer patients treated with stereotactic body radiotherapy. J Clin Oncol 27:3290-3296

24. Fakiris AJ, McGarry RC, Yiannoutsos CT et al (2009) Stereotactic body radiation therapy for early-stage non-small-cell lung carcinoma: four-year results of a prospective phase II study. Int J Radiat Oncol Bio Phys 75:677-682

25. Ricardi U, Filippi AR, Guarneri A et al (2010) Stereotactic body radiation therapy for early stage nonsmall cell lung cancer: results of a prospective trial. Lung Cancer 68:72-77

26. Timmerman R, Paulus R, Galvin J et al (2010) Stereotactic body radiation therapy for inoperable early stage lung cancer. JAMA 303:1070-1076

27. Bral S, Gevaert T, Linthout N et al (2011) Prospective, risk-adapted strategy of stereotactic body radiotherapy for early-stage non-small-cell lung cancer: results of a Phase II trial. Int J Radiat Oncol Biol Phys 80:1343-1349

28. Grutters JP, Kessels AG, Pijls-Johannesma M et al (2010) Comparison of the effectiveness of radiotherapy with photons, protons and carbon-ions for non-small cell lung cancer: a meta-analysis. Radiother Oncol 95:32-40

29. Kopek N, Paludan M, Petersen J et al (2009) Comorbidity index predicts for mortality after stereotactic body radiotherapy for medically inoperable early-stage non-small cell lung cancer. Radiother Oncol 93:402-407

30. NCCN Clinical Practice Guidelines in Oncology: Non-small cell lung cancer Version 1.2013 [http:// www.ncen.org/]

31. Renaud S, Falcoz PE, Olland A, Massard G (2013) Is radiofrequency ablation or stereotactic ablative radiotherapy the best treatment for radically treatable primary lung cancer unfit for surgery? Interact Cardiovasc Thorac Surg 16:68-73
32. Crabtree T, Puri V, Timmerman R et al (2013) Treatment of stage I lung cancer in high-risk and inoperable patients: comparison of prospective clinical trials using stereotactic body radiotherapy (RTOG 0236), sublobar resection (ACOSOG Z4032), and radiofrequency ablation (ACOSOG Z4033). JThorac Cardiovasc Surg 145:692-699

33. Grills IS, Mangona VS, Welsh R et al (2010) Outcomes after stereotactic lung radiotherapy or wedge resection for stage I non-small-cell lung cancer. J Clin Oncol 28:928-935

34. Oshiro Y, Aruga T, Tsuboi K et al (2010) Stereotactic body radiotherapy for lung tumors at the pulmonary hilum. Strahlenther Onkol 186:274-279

35. Lagerwaard FJ, Verstegen NE, Haasbeek $\mathrm{CJ}$ et al (2012) Outcomes of stereotactic ablative radiotherapy in patients with potentially operable stage I non-small cell lung cancer. Int J Radiat Oncol Biol Phys 83:348-353

36. Senan S, Verstegen NE, Palma D et al (2012) Stages I-II non-small cell lung cancer treated using either lobectomy by video-assisted thoracoscopic surgery (VATS) or stereotactic ablative radiotherapy (SABR): outcomes of a propensity scorematched analysis. ASCO Meeting Abstracts 30(15_suppl):7009

37. Shelkey J, Fakiris A, DeCamp MM et al (2012) Matched-pair comparison of outcome of patients with clinical stage I non-small cell lung cancer treated with resection or stereotactic radiosurgery. ASCO Meeting Abstracts 30(15_suppl):7040

38. Bolliger CT, Wyser C, Roser H et al (1995) Lung scanning and exercise testing for the prediction of postoperative performance in lung resection candidates at increased risk for complications. Chest 108:341-348

39. Perrot M de, Licker M, Reymond MA et al (1999) Influence of age on operative mortality and longterm survival after lung resection for bronchogenic carcinoma. Eur Respir J 14:419-422

40. Swensen SJ, Silverstein MD, Ilstrup DM et al (1997) The probability of malignancy in solitary pulmonary nodules. Application to small radiologically indeterminate nodules. Arch Intern Med 157:849855

41. Herder GJ, Kramer H, Hoekstra OS et al (2006) Traditional versus up-front [18F] fluorodeoxyglucosepositron emission tomography staging of nonsmall-cell lung cancer: a Dutch cooperative randomized study. J Clin Oncol 24:1800-1806

42. Patel VK, Naik SK, Naidich DP et al (2013) A practical algorithmic approach to the diagnosis and management of solitary pulmonary nodules: part 2: pretest probability and algorithm. Chest 143:840-846

43. Patel VK, Naik SK, Naidich DP et al (2013) A practical algorithmic approach to the diagnosis and management of solitary pulmonary nodules: part 1: radiologic characteristics and imaging modalities. Chest 143:825-839

44. Verstegen NE, Lagerwaard FJ, Haasbeek $\mathrm{CJ}$ et al (2011) Outcomes of stereotactic ablative radiotherapy following a clinical diagnosis of stage I NSCLC: comparison with a contemporaneous cohort with pathologically proven disease. Radiother Oncol 101:250-254

45. Sawada S, Yamashita MK, Eisaku N et al (2007) Evaluation of resected tumors that were not diagnosed histologically but were suspected of lung cancer preoperatively. J Thorac Oncol 2:S422-S422

46. Murai T, Shibamoto Y, Baba F et al (2010) Progression of non-small-cell lung cancer during the interval before stereotactic body radiotherapy. Int J Radiat Oncol Biol Phys 82:463-467 
47. De Ruysscher D, Faivre-Finn C, Nestle U et al (2010) European organisation for research and treatment of cancer recommendations for planning and delivery of high-dose, high-precision radiotherapy for lung cancer. J Clin Oncol 28:5301-5310

48. Stiles BM, Servais EL, Lee PC et al (2009) Point: clinical stage IA non-small cell lung cancer determined by computed tomography and positron emission tomography is frequently not pathologic IA non-small cell lung cancer: the problem of understaging. J Thorac Cardiovasc Surg 137:13-19

49. Park HK, Jeon K, Koh WJ et al (2010) Occult nodal metastasis in patients with non-small cell lung cancer at clinical stage IA by PET/CT. Respirology 15:1179-1184

50. Wolthaus JW, Sonke JJ, Herk M van et al (2008) Comparison of different strategies to use four-dimensional computed tomography in treatment planning for lung cancer patients. Int J Radiat Oncol Biol Phys 70:1229-1238

51. Guckenberger M, Krieger T, Richter A et al (2009) Potential of image-guidance, gating and real-time tracking to improve accuracy in pulmonary stereotactic body radiotherapy. Radiother Oncol 91:288295

52. Paddick I (2000) A simple scoring ratio to index the conformity of radiosurgical treatment plans. Technical note. J Neurosurg 93(Suppl 3):219-222

53. Lagerwaard FJ, Haasbeek CJ, Smit EF et al (2008) Outcomes of risk-adapted fractionated stereotactic radiotherapy for stage I non-small-cell lung cancer. Int J Radiat Oncol Biol Phys 70:685-692

54. Onishi H, Araki T, Shirato H et al (2004) Stereotactic hypofractionated high-dose irradiation for stage I nonsmall cell lung carcinoma: clinical outcomes in 245 subjects in a Japanese multiinstitutional study. Cancer 101:1623-1631

55. Wulf J, Baier K, Mueller G, Flentje MP (2005) Doseresponse in stereotactic irradiation of lung tumors. Radiother Oncol 77:83-87

56. Guckenberger M, Wulf J, Mueller G et al (2009) Dose-response relationship for image-guided stereotactic body radiotherapy of pulmonary tumors: relevance of 4D dose calculation. Int J Radiat Oncol Biol Phys 74:47-54

57. Grills IS, Hope AJ, Guckenberger M et al (2012) A collaborative analysis of stereotactic lung radiotherapy outcomes for early-stage non-small-cell lung cancer using daily online cone-beam computed tomography image-guided radiotherapy. J Thorac Oncol 7:1382-1393

58. Onimaru R, Fujino M, Yamazaki K et al (2008) Steep dose-response relationship for stage I non-smallcell lung cancer using hypofractionated high-dose irradiation by real-time tumor-tracking radiotherapy. Int J Radiat Oncol Biol Phys 70:374-381

59. Zhang J, Yang F, Li B et al (2011) Which is the optimal biologically effective dose of stereotactic body radiotherapy for Stage I non-small-cell lung cancer? A meta-analysis. Int J Radiat Oncol Biol Phys 81:e305-e316

60. Guckenberger M, Allgauer M, Appold S. Dieckmann K, Ernst I, Ganswindt U, Holy R, Nestle U, Nevinny-Stickel M, Semrau S et al (2013) Safety and efficacy of stereotactic body radiotherapy for stage I non-small-cell lung cancer in routine clinical practice. Patterns-of-care and outcome analysis. J Thorac Oncol 8:1050-1058

61. Haedinger U, Krieger T, Flentje M, Wulf J (2005) Influence of calculation model on dose distribution in stereotactic radiotherapy for pulmonary targets. Int J Radiat Oncol Biol Phys 61:239-249
62. Senthi S, Haasbeek CJ, Slotman BJ, Senan S (2013) Outcomes of stereotactic ablative radiotherapy fo central lung tumours: a systematic review. Radiother Oncol 106:276-282

63. Timmerman R, McGarry R, Yiannoutsos C et al (2006) Excessive toxicity when treating central tumors in a phase II study of stereotactic body radiation therapy for medically inoperable early-stage lung cancer. J Clin Oncol 24:4833-4839

64. Hurkmans CW, Cuijpers JP, Lagerwaard FJ et al (2009) Recommendations for implementing stereotactic radiotherapy in peripheral stage IA nonsmall cell lung cancer: report from the Quality Assurance Working Party of the randomised phase III ROSEL study. Radiat Oncol 4:1

65. Wulf J, Hadinger U, Oppitz U et al (2003) Impact of target reproducibility on tumor dose in stereotactic radiotherapy of targets in the lung and liver. Radiother Oncol 66:141-150

66. Guckenberger M, Meyer J, Wilbert J et al (2006) Cone-beam CT based image-guidance for extracranial stereotactic radiotherapy of intrapulmonary tumors. Acta Oncol 45:897-906

67. Guckenberger M, Heilman K, Wulf J et al (2007) Pulmonary injury and tumor response after stereotactic body radiotherapy (SBRT): results of a serial follow-up CT study. Radiother Oncol 85:435-442

68. Takeda T, Takeda A, Kunieda E et al (2004) Radiation injury after hypofractionated stereotactic radiotherapy for peripheral small lung tumors: serial changes on CT. AJR Am J Roentgenol 182:11231128

69. Kimura T, Matsuura K, Murakami Y et al (2006) CT appearance of radiation injury of the lung and clinical symptoms after stereotactic body radiation therapy (SBRT) for lung cancers: are patients with pulmonary emphysema also candidates for SBRT for lung cancers? Int J Radiat Oncol Biol Phys 66:483-491

70. Dunlap NE, Yang W, McIntosh A et al (2012) Computed tomography-based anatomic assessment overestimates local tumor recurrence in patients with mass-like consolidation after stereotactic body radiotherapy for early-stage non-small cell lung cancer. Int J Radiat Oncol Biol Phys 84:10711077

71. Huang K, Dahele M, Senan S et al (2012) Radiographic changes after lung stereotactic ablative radiotherapy (SABR) — can we distinguish recurrence from fibrosis? A systematic review of the literature. Radiother Oncol 102:335-342

72. Fuks Z, Kolesnick R (2005) Engaging the vascular component of the tumor response. Cancer cell 8:89-91

73. Lee Y, Auh SL, Wang Y et al (2009) Therapeutic effects of ablative radiation on local tumor require CD8+T cells: changing strategies for cancer treatment. Blood 114:589-595

74. Kirkpatrick JP, Meyer JJ, Marks LB (2008) The linearquadratic model is inappropriate to model high dose per fraction effects in radiosurgery. Semin Radiat Oncol 18:240-243

75. Brenner DJ (2008) The linear-quadratic model is an appropriate methodology for determining isoeffective doses at large doses per fraction. Semin Radiat Oncol 18:234-239

76. Haasbeek CJ, Lagerwaard FJ, Slotman BJ, Senan $S$ (2011) Outcomes of stereotactic ablative radiotherapy for centrally located early-stage lung cancer. J Thorac Oncol 6:2036-2043.
77. Dunlap NE, Cai J, Biedermann GB et al (2010) Chest wall volume receiving $>30$ Gy predicts risk of severe pain and/or rib fracture after lung stereotactic body radiotherapy. Int J Radiat Oncol Biol Phys 76:796-801

78. Stephans KL, Djemil T, Tendulkar RD et al (2012) Prediction of chest wall toxicity from lung stereotactic body radiotherapy (SBRT). Int J Radiat Oncol Biol Phys 82:974-980 